\title{
Desenvolvimento Organizacional Multidimensional: uma perspectiva crítica para os estudos organizacionais
}

\author{
Fernando Batista Bandeira da Fontoura \\ Universidade de Santa cruz do Sul - Santa cruz do Sul - RS - Brasil \\ ORCID: https://orcid.org/0000-0002-9484-8963 \\ Fernando Guilherme Tenório \\ Fundação Getúlio Vargas - Rio de Janeiro - RJ - Brasil \\ ORCID: https://orcid.org/0000-0003-4082-4410
}

\section{Resumo}

Esta pesquisa teve como objetivo identificar se a perspectiva do Desenvolvimento Organizacional Multidimensional (DOM) é adequada teoricamente para explicar processos de desenvolvimento das organizações em um contexto de desenvolvimento regional. Compreende-se o DOM como uma possibilidade de revisão das formas e métodos organizacionais de desenvolvimento. A abordagem teórica faz uma revisão crítica sobre a "teoria" do Desenvolvimento Organizacional (DO), considerando os aspectos sistêmicos, estruturais e empresariais (multidimensionais) para além da cultura de consumo e da ênfase no lucro, relacionadas com a territorialidade e a sustentabilidade. Ramos (1989), Tenório (2004; 2007; 2011) e De Paula (2015).

Palavras-chave: Desenvolvimento Organizacional Multidimensional. Desenvolvimento regional. Métodos organizacionais de desenvolvimento.

\section{Multidimensional Organizational Development: a critical perspective for organizational} studies

\section{Abstract}

The objective of this research was to identify if the perspective of the Multidimensional Organizational Development (MOD) was theoretically suitable to explain the development process of organizations in a regional development context. The MOD it's known as a chance to review the ways and organizational methods of development. The theoretical approach brings a critical review about the Organizational Development (OD)'s "theory", considering the systemic, structural and business (multidimensional) aspects to beyond the consumer culture and the profit emphasis, related to territoriality and sustainability. In this way, as the main construct, it is noticed that the systemic, structural and business factors as categories and possibilities of MOD that line up to the vision of epistemic reconstruction in the organizations studies defended by Ramos (1989), Tenório (2004; 2007; 2011) and De Paula (2015).

Keywords: Multidimensional Organizational Development. Regional development. Organizational methods of development. 


\section{Desarrollo Organizacional Multidimensional: una perspectiva crítica para los estudios} organizacionales

\section{Resume}

Esta investigación tuvo como objetivo identificar si la perspectiva del Desarrollo Organizacional Multidimensional (DOM) es adecuada teóricamente para explicar procesos de desarrollo de las organizaciones en un contexto de desarrollo regional. Se entiende el DOM como una posibilidad de revisión de las formas y métodos organizacionales de desarrollo. El enfoque teórico hace una revisión crítica sobre la "teoría" del desarrollo organizacional (DO), considerando los aspectos sistémicos, estructurales y empresariales (multidimensionales) más allá de la cultura del consumo y del énfasis en el lucro, relacionadas con la territorialidad y la sostenibilidad. Así, como principal constructo, se percibe los factores sistémicos, estructurales y empresariales como categorías y posibilidades de DOM alineado a la visión de reconstrucción epistémica en los estudios organizacionales, defendida por Ramos (1989), Tenório (2004; 2007; 2011) y De Paula (2015).

Palabras clave: Desarrollo Organizacional Multidimensional. Desarrollo regional. Métodos organizativos de desarrollo.

\section{Introdução}

As organizações, de modo geral, buscam novas formas para constituir suas relações de produção, tanto por pessoas que atuam nesses espaços como por alterações culturais, históricas, e sociais presentes em diferentes formações espaciais. (BENKO, 1999). A teoria do Desenvolvimento Organizacional (DO) descrita na literatura de gestão é originária de conceitos historicamente limitados a apresentar alternativas voltadas para a eficiência e a eficácia dos processos organizacionais, visões características da sociedade industrial e não alinhadas à visão pós-industrial que é analisada nesta pesquisa. Neste constructo, o desenvolvimento organizacional (que abrange níveis ou campos variados) constituise uma alternativa para dinamizar diferentes perfis organizacionais, pois as mudanças que envolvem o desenvolvimento regional, de forma interdisciplinar, apresentam características policêntricas.

Questões policêntricas são aquelas que apresentam vários centros de direção e de decisão. Essa visão alinha-se ao modelo multicêntrico, em que o mercado não pode ser considerado como o único centro nos estudos organizacionais, conforme proposto por Ramos (1996). As variáveis polimórficas (mudanças de formas e estruturas) exigem constantes debates e revisão de suas práticas periodicamente. Vale dizer que as mudanças policêntricas ocorrem nas esferas sociais e organizacionais, envolvendo dinâmicas contextualizadas por uma visão multifatorial (fatores de diferentes naturezas). As mudanças polimórficas, por sua vez, constituem-se de variadas formas, sendo que o mercado é apenas o cenário onde ocorrem alterações pouco controláveis, mas essenciais para a manutenção de estruturas organizacionais.

Como tentativa de teoria administrativa, O DO demonstra caráter mais instrumental. Autores como Sobral e Peci (2013) contribuem para o entendimento, enfatizando que os estudos organizacionais apresentam predominantemente os aspectos internos, no máximo prevendo políticas internas de recursos humanos, raramente evoluindo para dimensões macroambientais e sociais abordadas neste 
estudo e consideradas como multidimensionais (KUPFER; FERRAZ; HAGUENAUER, 1997).

O DO necessita de refinamento teórico e metodológico em função da complexidade social e organizacional da sociedade contemporânea. Para tanto, fazse necessário incorporar uma nova abordagem às teorias da Administração pautadas em uma reflexão epistemológica e contextualizada que envolva a análise das formas de organização da produção e do desenvolvimento econômico, descritas neste estudo como macroperíodos - pré-industrial, industrial e pósindustrial -, assim como definição de um marco teórico para o DOM.

É nesse contexto que se desenvolve a teoria do desenvolvimento organizacional com foco na mudança, através de consultorias empresariais e da busca da eficiência dos sistemas produtivos, descritos na obra de Bennis (1972). O ponto de partida da discussão é a unidimensionalidade do DO, contestando-se, inclusive, a categoria de teoria organizacional. Entende-se que, para ser denominado como tal, o DO deveria apresentar um arcabouço teórico e epistemológico mais refinado, envolvendo questões sociais e ambientais e não somente a eficiência organizacional, bem como prestar atenção às questões regionais, já observadas criticamente por Ramos (1989; 1996).

O conceito de multidimensionalidade é apresentado por Marcuse (1973), que reconhece o homem como um ser unidimensional, alienado na sua forma de ver o mundo e de reconhecer as alterações sociais presentes na sociedade industrial. Vale mencionar que Horkheimer (1974, p. 42) contribui com esse raciocínio, inferindo que "[...] o homem se encontra alienado na fábrica e no escritório", ou seja, em todos os ambientes de trabalho, em todos os setores, ou na maioria deles, não existe uma visão emancipada das ações e dos efeitos causados pela sociedade industrial.

Os estudos organizacionais devem ser desenvolvidos considerando-se toda a complexidade das relações entre as empresas, vistas como espaços de interação com o ambiente. Esses estudos, muitas vezes, são insuficientes para analisar a complexidade organizacional, como aponta Ramos (1989), em função de algumas contradições, como constantes movimentos dos contrários, entre a produtividade e a humanização, o fordismo e as possibilidades pós-fordistas, entre as escalas local, regional, nacional e internacional.

Assim, o DOM pode ser uma possibilidade de refinamento dos estudos organizacionais e regionais, visto que a literatura em gestão, na maioria dos casos, é desenvolvida de forma isomórfica em outros países (RAMOS, 1989; MORGAN, 1996; DIMÁGGIO; POWELL, 2005; TENÓRIO, 2004; BOLTANSKI; CHIAPELLO, 2009; SOBRAL; $\mathrm{PECl}$, 2013). Além disso, pode contribuir, mesmo que indiretamente, para o aprimoramento social (GRZYBOVSKI, 2014).

Ao analisar os estudos organizacionais e as dinâmicas empresariais com vistas à elaboração de uma perspectiva teórica sobre o desenvolvimento organizacional que envolva a sociedade, as pessoas e as organizações, constata-se uma série de contradições. Com base nos elementos referidos, apresenta-se o seguinte questionamento: A perspectiva do DOM é adequada teoricamente à explicação de processos de desenvolvimento organizacional em um contexto de desenvolvimento regional?

Em uma perspectiva não paradigmática, Khun (2005), como defendido nos estudos organizacionais por Morgan (1996) no contexto internacional, esse ensaio 
alinha-se aos estudos de De Paula (2015; 2016), através de uma visão de reconstruções epistêmicas e da impossibilidade de padronização da realidade organizacional e social que parece adequada para reformulações organizacionais.

Apesar da incompletude cognitiva das matrizes epistemológicas nos estudos organizacionais, apresenta-se neste artigo a contextualização histórica dos macroperíodos de organização da produção, as contribuições das matrizes do conhecimento científico e uma possibilidade de se pensar no DOM para reflexão nos processos de planejamento e desenvolvimento das organizações no contexto regional.

\section{Contextualização histórica e matrizes epistemológicas nos estudos organizacionais}

A análise epistemológica do desenvolvimento das organizações e dos mercados pressupõe uma compreensão sobre os macroperíodos do desenvolvimento. Nesse sentido, identifica-se que a organização da produção foi historicamente influenciada pelo sistema econômico de acumulação do capital e, também, pelo desenvolvimento das organizações, de acordo com macroperíodos históricos ${ }^{1}$.

Marx (1974) e autores das Escolas Econômicas Clássicas, como Ricardo (1982), Malthus (1982) e Smith (1996), contribuíram para a análise da relação entre o capital e o trabalho. Os economistas clássicos preocuparam-se com a noção de riqueza centrada nos fatores tangíveis de produção, sendo que Marx focou-se nas relações de trabalho e nas classes sociais, contribuindo para a visão atual de fenonomias (RAMOS, 1996).

Para entender o desenvolvimento organizacional e as formas de organização da produção, partindo-se de uma ontologia não positivista, o entendimento dos modelos econômicos figura como aspecto fundamental de partida, visto que, nos dias de hoje, é inegável a crise do sistema de acumulação rígida do capital (HARVEY, 1992; TOFFLER, 1995; TENÓRIO, 2007). As organizações capitalistas não estão imunes às crises ocasionadas por questões regionais, territoriais, culturais e sociais. Independente do porte, as empresas não desenvolveram uma estrutura de gestão preparada para competir com as possibilidades pós-industriais. A gestão, hegemonicamente, foca-se na eficiência e na eficácia baseada na contribuição weberiana, (Weber foi um autor que analisou a sociedade e influenciou as organizações), estando atrelada, também, a teorias externas e aos mercados massificados.

Enquanto as economias externas dependem do desenvolvimento da indústria, as economias internas dependem dos recursos e da gestão da própria empresa, da eficiência da sua administração, enfim, da sua atuação no mercado, que estimula processos novos e acirradas dinâmicas de concorrência. As relações de produção, assim como o DO, tiveram uma evolução histórica com inúmeras contradições, principalmente porque as organizações e as teorias organizacionais tendem ao unidimensionalismo e à alienação nas relações.

\footnotetext{
${ }^{1}$ Uma parte das discussões presentes neste item foram originalmente publicadas no artigo científico intitulado "Organizações e desenvolvimento: reflexões epistemológicas (FONTOURA; WITTMANN, 2016).
} 
O DO ocorreu influenciado pelo desenvolvimento da sociedade industrial, apresentando características unidimensionais e ligadas ao modelo de produção industrial (MARCUSE, 1973; HORKHEIMER; ADORNO, 1985; HORKHEIMER, 1974). Nesse contexto, a visão de mundo positivista não só influenciou os modelos de produção, mas predominou no comportamento e na organização da sociedade como um todo, desenvolvendo uma espécie de "taylorismo do espírito" que também influenciou as escolas e as teorias da administração (MORGAN, 1996; RAMOS, 1989).

Entretanto, no final do século XX, a globalização e a inovação passaram a ser protagonistas de um novo ciclo dito "de desenvolvimento", entendido nesta pesquisa apenas como crescimento econômico unidimensional, com alguns traços de flexibilização em alguns casos. As novas tecnologias nos transportes, nas comunicações e no acesso às informações fortaleceram processos de interação entre organizações, aumentando a complexidade interativa e a necessidade de se criarem ambientes que privilegiassem relações interempresariais. Assim, cidades e regiões passaram a dar respostas estratégicas aos desafios gerados pela nova dinâmica concorrencial, não apenas através da oferta de novos produtos e serviços, mas pela criação de ambientes complexos e interativos, alinhados ao desenvolvimento regional territorializado. Contudo, Harvey (1992, p. 1) adverte que "essas mudanças, quando confrontadas com as regras básicas de acumulação capitalista, mostram-se mais como transformações de aparência superficial do que como sinais do surgimento de alguma sociedade pós-capitalista, ou mesmo pósindustrial inteiramente nova".

Apesar da crítica de Harvey, em função da necessidade de revisão de paradigmas organizacionais baseados no crescimento, utiliza-se a expressão "possibilidades pós-industriais" ao mencionar mercados, face às mudanças aceleradas dos ambientes e das organizações e o desenvolvimento embrionário de teorias e de ações de desenvolvimento organizacioal, considerados como alternativas para o desenvolvimento regional.

O Quadro 1 resume as características dos macroperíodos de organização da produção, partindo do modelo pré-industrial, caracterizado pelo trabalho artesanal, tendo como proprietário o artífice, com formação baseada nas demandas locais e com conhecimento restrito ao transmitido pela família, passado de geração para geração. Já a organização neotaylorista/fordista descreve as características dos regimes de acumulação com os principais focos organizacionais e territoriais, inclusive com possibilidades pós-industriais. Acredita-se que esses elementos contribuem para a análise dos regimes de acumulação, das mudanças nos ambientes organizacionais e territoriais, assim como para a realização de um contraponto à teoria organizacional, hegemonicamente positivista.

O termo neotaylorista/neofordista, na verdade, não seria sinônimo de pósindustrial, mas um estágio de transição com algumas características de acumulação flexível e gestão social, sendo o termo pós-industrial mais amplo, apresentando uma leitura econômica e de organização da produção propriamente dita, fomentada pelas alterações sociais e por seu impacto nas dinâmicas regionais do desenvolvimento. ${ }^{2}$

\footnotetext{
2 A literatura nacional e a internacional, na atualidade, discutem também a quarta revolução industrial como novo paradigma histórico e social, mencionando os avanços tecnológicos e
} 
A empresa taylorista/fordista possui conhecidas características citadas por Harvey (1992), Etges (2005) e Tenório (2004; 2007), com predomínio de elementos como o aumento da produção em massa e dos lucros, alinhados às patologias sociais e organizacionais ligadas à motivação do trabalhador e à organização do trabalho industrial. As organizações neotayloristas/neofordistas ou pós-industriais poderiam denominar-se organizações alinhadas ao desenvolvimento de uma região, sendo abordadas, neste estudo, as voltadas à sustentabilidade econômica, social, cultural e ambiental, com ações em múltiplas direções, como contra-resposta ao modelo econômico hegemônico capitalista. Contudo, essa ainda não é a realidade que se observa disseminada na atualidade.

\begin{tabular}{|c|l|l|}
\hline \multicolumn{1}{|c|}{ Quadro 1-Macroperíodos do desenvolvimento } \\
\hline Estágios & \multicolumn{1}{|c|}{ Características } & \multicolumn{1}{c|}{ Propriedade e território } \\
\hline Pré-industrial & $\begin{array}{l}\text { Produção artesanal } \\
\text { Agricultura rudimentar } \\
\text { Terra como poder social }\end{array}$ & $\begin{array}{l}\text { Vinculada ao artífice } \\
\text { Produção e mercado } \\
\text { territorializado } \\
\text { Território pertencente a } \\
\text { famílias e clãs }\end{array}$ \\
\hline $\begin{array}{c}\text { Industrial } \\
\text { Taylorista/Fordista }\end{array}$ & $\begin{array}{l}\text { Produção planejada e } \\
\text { rotinizada } \\
\text { Produção em massa } \\
\text { Capital como poder social }\end{array}$ & $\begin{array}{l}\text { Proprietário do capital } \\
\text { Processos de produção } \\
\text { Mercados transnacionais }\end{array}$ \\
\hline $\begin{array}{c}\text { Pós-industrial ou } \\
\text { Neotaylorista } \\
\text { /Neofordista }\end{array}$ & $\begin{array}{l}\text { Acumulação flexível } \\
\text { Gestão territorial } \\
\text { Autopoiese e } \\
\text { sustentabilidade } \\
\text { Inovação, mudança e } \\
\text { conhecimento como poder } \\
\text { social }\end{array}$ & $\begin{array}{l}\text { Propriedade sob investidor } \\
\text { Ambiente globalizado } \\
\text { Territórios, processos e } \\
\text { mercados multidimensionais e } \\
\text { multiescalares }\end{array}$ \\
\hline $\begin{array}{l}\text { Fonte: Adaptado de: } \\
\text { (2001);Bell, (1977, 1973); } \text { Tenório, (2004); Marcuse,(1973); }\end{array}$
\end{tabular}

A abordagem dos macroperíodos, neste estudo, não está alinhada à perspectiva de modelos prontos, visto que as organizações, ainda na atualidade, pela lógica do movimento dos contrários, apresentam características pré-industriais, industriais (ainda hegemônica), e possibilidades pós-industriais, sem entrar ainda no mérito das revoluções industriais já apresentadas na literatura de gestão.

cognitivos na organização social e do trabalho, com destaque para a sociedade conexionista e os avanços na área da nanotecnologia, produção agroindustrial, entre vários segmentos de produção. Esta pesquisa não se preocupa com classificações fechadas e nomenclaturas classificativas, definindo pós-industrial, industrial ou quarta revolução industrial, não desprezando a bibliografia sobre o tema. Para uma abordagem crítica, importa reforçar que o pré-industrial contém o seu contrário, que é o industrial em algum período histórico; o industrial contém o seu contrário, que é o artífice em alguns processos e também possibilidades pós-industriais com o início dos processos de flexibilização; e o pós-industrial ou sociedade da informação, como definido por Boltanski e Chiapello (2009), contém contradições das mais variadas, visto que o próprio Harvey (1992) já advertia sobre a utopia da sociedade pós-industrial plena. Por essas rações, este estudo apresenta os macroperíodos como contexto histórico, sem grandes preocupações com definições "caixas", o que seria uma contradição em relação aos objetivos da pesquisa. 
Após apresentar a contextualização histórica dos macroperíodos de organização da produção para o constructo da pesquisa, uma análise sobre as matrizes epistemológicas do conhecimento torna-se importante para a análise crítica dos estudos organizacionais.

Como ponto de partida, apresentam-se as matrizes epistemológicas (Positivismo, Materialismo Histórico e Teoria da Complexidade), a partir de uma análise pautada na Teoria Crítica influenciada por Marx (1974), conhecida também como Escola de Frankfurt, com origem em Horkheimer (1974), seguida por Horkheimer e Adorno (1985), Marcuse (1973) e Habermas (2004).

Assim, este artigo baseia-se na compreensão das estruturas organizacionais, tendo como referência as matrizes epistemológicas, as teorias e as escolas de administração que influenciaram o desenvolvimento das empresas consideradas ambientes de acumulação capitalista. As análises sobre as categorias de desenvolvimento e organizações estão relacionadas com a compreensão do DO, contextualizado pelas matrizes epistemológicas, teorias e escolas de administração, em uma perspectiva reflexiva, estabelecendo-se um contraponto à visão positivista e empirista, ainda predominante nos estudos organizacionais. Busca-se compreender os estágios do DO a partir de uma reflexão epistemológica contextualizada pelos macroperíodos de organização da produção e pelas estratégias organizacionais, bem como tendo por base elementos multidimensionais que envolvem o ambiente interno e externo, as relações das dinâmicas organizacionais com a sociedade e com o mercado.

O ponto de partida refere-se à visão multicêntrica, já defendida por Guerreiro Ramos (1996), em que o mercado é apenas uma das variáveis a ser analisada e não a única dimensão predominante, conforme descrito na literatura sobre gestão empresarial. Tenório $(1998 ; 2011)$ contribui com essa análise ao mencionar que, a partir de uma perspectiva social, a sociedade é o aspecto fundamental de uma análise crítica sobre os estudos organizacionais, tornando-se o fundamento inicial para se pensar em Desenvolvimento Organizacional Multidimensional.

Em uma análise preliminar, as matrizes epistemológicas seriam consideradas macroparadigmas que influenciam o desenvolvimento teórico, as escolas, as teorias e as estruturas, bem como os "modismos organizacionais" presentes na cognição humana e na condição organizacional. Etimologicamente, o termo matriz lembra um processo tipográfico de cópia. Entretanto, sob uma visão emancipatória, essa simplicidade possui o seu contrário, que seria uma análise mais complexa, no sentido de alertar que as matrizes inspiram processos cognitivos, seguidos por métodos e teorias que não consideram a devida reflexão dos estudos organizacionais, conforme a visão de reconstrução epistêmica de De Paula (2015).

É ainda De Paula (2016) que define como matriz epistemológica a matriz empírico-analítica alinhada à lógica formal, à filosofia positiva de interesse técnico, à matriz hermenêutica de lógica interpretativa e de interesses práticos, e à matriz crítica de filosofia negativa de lógica dialética e de interesse emancipatório. Já Ziemer (1996) argumenta que as matrizes epistemológicas são insuficientes para atender as demandas de cada caso, de cada empresa, ou seja, a análise epistemológica vai depender de diferentes filosofias e de interesses estratégicos/cognitivos. "A dinâmica das abordagens sociológicas no círculo das 
matrizes epistêmicas é animada pelas teses da incompletude cognitiva e das reconstruções epistêmicas" (DE PAULA, 2016).

Os estudos organizacionais e sociais historicamente destacam a matriz positivista de interesse predominantemente técnico que influenciou 0 desenvolvimento prático e tecnológico, com forte participação no desenvolvimento científico. Apresenta-se, no quadro 2, uma síntese das matrizes epistemológicas comumente descritas na literatura.

\section{Quadro 2 - Fundamentos e histórico das matrizes epistemológicas}

\begin{tabular}{|c|c|}
\hline $\begin{array}{c}\text { Matriz } \\
\text { epistemológica }\end{array}$ & Histórico e fundamentos \\
\hline $\begin{array}{c}\text { Positivismo } \\
\text { Auguste Compte }\end{array}$ & $\begin{array}{l}\text { Doutrina filosófica, sociológica e política cujo surgimento deu-se com o desenvolvimento } \\
\text { sociológico do lluminismo, das crises social e moral do fim da Idade Média e do nascimento } \\
\text { da Sociedade Industrial - processos que tiveram como grande marco a Revolução Francesa } \\
\text { (1789-1799) (TRINDADE, 2007). Vale ressaltar que o Positivismo defende a ideia de que o } \\
\text { conhecimento científico é a única forma de conhecimento verdadeiro. De acordo com os } \\
\text { positivistas, somente se pode afirmar que uma teoria é correta se ela for comprovada } \\
\text { através de métodos científicos válidos. Seu principal representante foi o francês Auguste } \\
\text { Comte (1758-1857) (TRINDADE, 2007). "Ler para prever" é o seu lema. O conhecimento } \\
\text { científico torna-se instrumento de transformação da realidade, do domínio do homem } \\
\text { sobre a natureza. Método indutivo, busca da objetividade, instrumentalização e } \\
\text { quantificação. }\end{array}$ \\
\hline $\begin{array}{l}\text { Pós-positivismo } \\
\text { Karl Popper }\end{array}$ & $\begin{array}{l}\text { Versão do Positivismo que reconhece o realismo ontológico, a possibilidade e o desejo pela } \\
\text { verdade objetiva e o uso da metodologia experimental. É comum nas ciências sociais, } \\
\text { especialmente na Sociologia, por razões práticas e conceituais. Surgiu no século XX e } \\
\text { aponta que o raciocínio científico é bastante semelhante ao raciocínio do senso comum. } \\
\text { Cada método pode ter erros, e os erros podem ser evitados se um maior número de } \\
\text { métodos for usado. Pressupõe que os cientistas NUNCA são objetivos e que são } \\
\text { tendenciosos devido às suas crenças culturais, negando o princípio da neutralidade. }\end{array}$ \\
\hline $\begin{array}{c}\text { Materialismo } \\
\text { Histórico } \\
\text { Marx e Engels }\end{array}$ & $\begin{array}{l}\text { Fundamenta-se na análise da realidade a partir da teoria da infraestrutura e superestrutura } \\
\text { que circundam determinado modo de produção. Com o aumento dos centros urbanos e da } \\
\text { industrialização no século XIX, na Europa, a desigualdade entre as classes se tornou cada } \\
\text { vez mais expressiva. Assim, o Materialismo Histórico buscou compreender as relações entre } \\
\text { o trabalho e os fatos materiais (econômicos, históricos ou técnicos) adquiridos ao longo da } \\
\text { história. Marx faz uma análise crítica sobre o sistema capitalista e a luta de classes entre } \\
\text { burguesia e proletariado. Como filosofia, visa explicar como se formaram as classes sociais } \\
\text { e, posteriormente, o Estado, sendo que este possui dois momentos: } 1 \text {. Surge para evitar ou } \\
\text { amenizar conflitos entre as classes. 2. Torna-se parcial, representando interesses das } \\
\text { classes dominantes, servindo como aparelho de coerção contra as classes dominadas. }\end{array}$ \\
\hline $\begin{array}{c}\text { Teoria Crítica } \\
\text { Escola de } \\
\text { Frankfurt }\end{array}$ & $\begin{array}{l}\text { A Escola de Frankfurt e, por conseguinte, a Teoria Crítica, institucionalizaram-se no final da } \\
\text { década de 1940, justamente com o fim da Segunda Guerra Mundial. Uma de suas principais } \\
\text { características é a fragmentação numa série de estudos, muitos antagônicos e } \\
\text { contraditórios. Na verdade, seu surgimento data de 1924, e um de seus principais objetivos } \\
\text { era explicar, historicamente, como se dava a organização e a consciência dos trabalhadores } \\
\text { industriais. Contesta o conceito de cultura de massa, propondo, em substituição, o conceito } \\
\text { de indústria cultural. Propõe a dialética como método para entender a sociedade (em sua } \\
\text { formação capitalista e na industrialização), fazendo a crítica da economia política ao tentar } \\
\text { entender o desemprego, o terrorismo e o militarismo que vedam a verdade ao ignorar que } \\
\text { suas intervenções constantemente incidem no contexto social. }\end{array}$ \\
\hline $\begin{array}{c}\text { Teoria da } \\
\text { Complexidade } \\
\text { Edgar Morin }\end{array}$ & $\begin{array}{l}\text { O pensamento complexo de Edgar Morin vê o mundo como um todo indissociável e propõe } \\
\text { uma abordagem multidisciplinar e multirreferenciada para a construção do conhecimento. } \\
\text { O conhecimento rejeita a desordem, a ambiguidade e a incerteza, mas a abordagem } \\
\text { transdisciplinar dos fenômenos pressupõe a mudança de paradigma através da pluralidade } \\
\text { de visões sobre um mesmo assunto, da retirada do absolutismo da verdade científica e do } \\
\text { ingresso da imprevisibilidade nos contextos biológico, sociológico, antropológico e } \\
\text { planetário. }\end{array}$ \\
\hline
\end{tabular}

Fonte: HORKHEIMER, 1974; POPPER,2004; MORIN, 2011. 
Neste estudo optou-se por analisar algumas matrizes epistemológicas, como o Positivismo (matriz empírico-analítica), devido à sua influência no desenvolvimento das organizações e nas formas de organização da produção; o Materialismo Histórico Dialético (matriz crítica), como método de análise da pesquisa e como influenciador do pensamento crítico; e a Visão Sistêmica e a Teoria da Complexidade, também com viés crítico nos estudos organizacionais, conforme apontado por Sobral e Peci (2013), Fontoura e Wittmann (2016).

As matrizes são mencionadas como delineadoras e macronarrativas que influenciaram o desenvolvimento da sociedade, das tecnologias, das formas de organização da produção e, por consequência, das organizações que fundamentam os dados primários dos estudos. Pretende-se evidenciar a influência de diferentes matrizes filosóficas e da Teoria Crítica nos processos desenvolvidos em contextos organizacionais em uma sociedade supersimbólica de múltiplas possibilidades, já não análoga à visão paradigmática predominante nos estudos organizacionais.

\section{DO versus DOM, um ensaio de marco teórico}

A teoria do DO originou-se dos estudos organizacionais e se desenvolveu especialmente a partir de investigações ligadas à Teoria Comportamental. Com base em uma visão crítica e voltada para o desenvolvimento regional, o desenvolvimento organizacional pode ser compreendido como algo mais amplo, contemplando todas as dimensões do desenvolvimento empresarial nas suas várias escalas. Esta pesquisa parte da contextualização histórica dos macroperíodos de organização da produção, considerados como paradigmas que influenciaram o desenvolvimento dos ambientes econômicos, os estudos organizacionais e as próprias organizações.

No contexto contemporâneo, as interações estruturais e superestruturais impulsionam a mudança organizacional no cotidiano, possuindo relação também com o momento vivido pelos sujeitos. Essas mudanças estão alicerçadas no desenvolvimento histórico, embora nem sempre estejam atreladas aos objetivos organizacionais (CRZYBOVSKI, 2014). Nessa perspectiva, o DO está associado aos conceitos de mudanças organizacionais planejadas e não ao conceito multidisciplinar e multidimensional de desenvolvimento. Este último (desenvolvimento) é um tema discutido, geralmente, de forma interdisciplinar nas ciências sociais e nas ciências sociais aplicadas, figurando como passível de várias interpretações, conforme referido por Scatolin (1989, p. 6):

\footnotetext{
Poucos são os outros conceitos nas Ciências Sociais que se têm prestado a tanta controvérsia. Conceitos como progresso, crescimento, industrialização, transformação, modernização, têm sido usados frequentemente como sinônimos de desenvolvimento. Em verdade, eles carregam dentro de si toda uma compreensão específica dos fenômenos e constituem verdadeiros diagnósticos da realidade, pois o conceito prejulga, indicando em que se deverá atuar para alcançar o desenvolvimento.
}

Siedenberg apud Crzybovski (2014, p. 4) ressalta o caráter interdisciplinar presente na definição do desenvolvimento e sua inter-relação com o DO: 
Com o tempo, a noção de desenvolvimento distanciou-se do pré-conceito de crescimento econômico e passou a referir-se a recortes territoriais específicos, pois, além de reencontrar a sua identidade, manifestou-se como uma nova área do conhecimento. Tornou-se marcado por um caráter interdisciplinar, que envolvia aspectos de âmbito econômico, social e ambiental. Assim, no contexto contemporâneo, o desenvolvimento mostra-se como a área do conhecimento interdisciplinar e que abrange várias subáreas, entre elas o desenvolvimento organizacional, objeto deste estudo.

No final da década de 1960, profissionais e pesquisadores perceberam que as alterações sociais vivenciadas provocavam impactos também nas organizações. Esse processo ocorreu sobretudo nos Estados Unidos, devido ao advento de uma sociedade pós-industrial que vivenciava o surgimento de novas tecnologias em variadas áreas do conhecimento, sem que as organizações estivessem preparadas para essa realidade (CARAVANTES; PANNO; KLOECKNER, 2005).

Diante dessa análise, as organizações começaram a planejar mudanças nos mecanismos de controle e de dominação, e a se preocupar com aspectos como liderança, motivação, "coaches”, entre outros. Começaram, então, a realizar ações que possibilitassem a participação dos próprios trabalhadores numa perspectiva de colaboração, conforme destacado por Boltanski e Chiapello (2009, p. 464):

\footnotetext{
Foi, portanto, muito estimulado o desenvolvimento de técnicas aptas a treinar as pessoas para que elas façam, aparentemente de modo voluntário, aquilo que se deseja que elas façam. Pensemos por exemplo no desenvolvimento de técnicas de comunicação (interna e externa), na corrente do DO que visa especialmente levar as pessoas a "tomar consciência" da existência de "problemas", previamente identificados pela direção para que depois seja mais fácil introduzir uma mudança no modo de organização.
}

O DO surge como tentativa de responder às mudanças nos ambientes e na percepção de consultores organizacionais e acadêmicos, com destaque para os estudos de Warren Bennis. Em sua obra Desenvolvimento organizacional: sua natureza, origens e perspectivas, Bennis (1972) menciona que as principais características que envolvem o DO podem ser expressas através de seis elementos, que são:

a) o DO parte de uma mudança nas organizações que envolve valores, atitudes e relações;

b) os problemas das organizações concentram-se em três categorias: I problemas de destino-crescimento, identidade e revitalização; II - problemas de desenvolvimento e satisfação das pessoas; III - problemas de eficiência organizacional;

c) as estratégias organizacionais dão prioridade ao comportamento já experimentado para construir, a partir dele, um novo comportamento por meio de um "efeito paradigma" (Kuhn, 2005);

d) os agentes de mudanças nas organizações normalmente são externos, como é o caso das consultorias especializadas; 
e) existe uma tendência à pouca colaboração entre o agente de mudança (consultor) e os componentes do sistema (clientes), o que pode dificultar a concretização dos objetivos;

f) os agentes de mudança compartilham uma filosofia social, uma visão de mundo também vinculada às questões socioambientais.

A análise das características do DO propostas por Bennis (1972) evidencia a existência de alguns avanços nas questões sociais e humanas. Entretanto, ainda há uma preocupação de cunho positivista com a eficiência organizacional, em geral disseminada por consultores organizacionais. Caravantes, Panno e Kloeckner (2005) salientam que o DO apresenta, em suas características iniciais, uma visão social centrada em aspectos internos e comportamentais (recursos humanos), muitas vezes direcionado para o aumento da produção e dos resultados através de maior satisfação no trabalho.

Percebe-se que o DO apresenta traços claros de conceitos da Teoria Comportamentalista, inclusive passível de críticas de autores como Ramos (1989) e Tenório (2007). Boltanski e Chiapello (2009) também evidenciaram que as práticas organizacionais de gestão participativa não dão possibilidades efetivas de participação aos trabalhadores no processo, sendo que, muitas vezes, induzem a uma "servidão voluntária".

O DO ainda é um tema pouco discutido nas ciências sociais aplicadas e apresenta uma genealogia mais interativa, apesar de contar com características positivistas, com influência da Teoria Comportamentalista, e da Teoria Contingencial e Sistêmica. Caravantes, Panno e Kloeckner (2005 p. 210) conceituam o DO como uma "[...] mudança planejada, articulada, pensada e não reativa ao sabor dos ventos". A obra de Bennis (1972) representou um marco para o DO e contribuiu para a mudança organizacional, devido à necessidade de busca de alternativas diante da crise dos modelos fordistas.

Oliveira (2012) refere que o DO não é reconhecido como uma teoria de forma unânime na Escola da Administração, mas sim como uma abordagem da Teoria Comportamentalista e Sistêmica. Bennis (1972) salienta que o DO surgiu com uma visão interna social vinculada ao desenvolvimento das pessoas, análise que talvez justifique a visão de autores das ciências administrativas.

Uma análise a partir de uma perspectiva dialética pressupõe que o DO não seja apenas comportamentalista, mas contenha vários traços dessa teoria, assim como elementos da visão sistêmica e contingencial estudada na Escola da Administração. Oliveira (2012, p. 195) apresenta o seguinte conceito de DO:

[...] um processo estudado para consolidar a mudança planejada dos aspectos estruturais e comportamentais nas organizações, com a finalidade de otimizar o processo de resolução de problemas e os resultados anteriormente estabelecidos nos planejamentos elaborados, sempre com adequado relacionamento interpessoal.

O conceito de DO está ainda atrelado às bases mecanicistas, à compreensão dos modos de produção centrados no lucro, alienados da essencial necessidade de revisão do processo de gestão e do debate sobre boas práticas na indústria. Ziemer (1996, p. 46) ressalta que: 
Em face das incertezas motivadas pelas grandes mudanças tecnológicas e econômicas, o referencial básico dos mitos ancorado em experiências e contextos passados da organização torna-se aos poucos, obsoleto. Daí a necessidade de revê-lo constantemente para assegurar sua atualidade. Caso contrário: limitam-se as habilidades técnicas e relacionais; reduz-se a capacidade crítica; gera-se conformidade às regras e valores superados da empresa; produz-se aparente coesão e espírito de equipe e torna-se deficiente o processo de tomada de decisões.

Por outro lado, o DO é considerado uma abordagem conceitual intermediária, por ser anterior à teoria do desenvolvimento, voltada para as questões multidimensionais de uma organização mais territorializada. Nesse contexto, Crzybovski (2014) apresenta uma contribuição mais sistêmica para a temática do DO, entendendo as organizações como sistemas abertos em um ambiente de múltiplas possibilidades. Segundo a autora,

O tema Desenvolvimento Organizacional mostra-se como parte integrante dos estudos do campo do comportamento organizacional, pois é um processo de mudanças planejadas que tem como intuito ampliar a competitividade das organizações e de forma indireta colabora para que haja modificações nos sistemas sociais. (CRZYBOVSKI, 2014, p. 4)

A análise histórica dos trabalhos acadêmicos realizados sobre a questão do DO evidencia a existência de três gerações das ciências administrativas analisadas, conforme pode ser observado através do Quadro 3. A primeira delas aponta para o surgimento do termo "desenvolvimento organizacional" aliado à eficiência e eficácia, evidenciando uma herança fortemente alicerçada na matriz positivista que foi hegemonicamente influenciadora dos estudos organizacionais, ainda predominante na atualidade. A segunda geração faz uma tentativa, mesmo que inicial, de incluir uma análise mais interativa das dimensões que constituem uma organização, apontando questões sociais, ambientais e comunitárias, principalmente a partir dos estudos de Bennis (1972). A terceira geração volta a focar-se na questão social, com o viés do desenvolvimento de recursos humanos, evidenciando o DO como teoria ou tentativa de teoria organizacional, atrelado aos aspectos internos, como advertido por Tenório (2004). 
Quadro 3 - Desenvolvimento organizacional e contribuições de seus representantes

\begin{tabular}{|c|c|c|}
\hline Autor & Ano & Contribuições \\
\hline \multicolumn{3}{|r|}{ Primeira geração } \\
\hline Richard Beckard & 1945 & $\begin{array}{l}\text { Criador da expressão “desenvolvimento organizacional”. } \\
\text { Coordenou a criação de grupos de treinamento organizacional para feedback. }\end{array}$ \\
\hline $\begin{array}{l}\text { Kurt Lewin e } \\
\text { William White }\end{array}$ & 1945 & $\begin{array}{l}\text { Consolidaram a pesquisa de ação, verificando o tempo real de cada tarefa } \\
\text { para melhoria e eficácia. }\end{array}$ \\
\hline Rensis Likert & 1946 & $\begin{array}{l}\text { Coordenou o desenvolvimento de pesquisa de entrevistas para feedback e } \\
\text { discursos junto aos empregados para melhoria nas condições de trabalho. }\end{array}$ \\
\hline $\begin{array}{l}\text { Eric L. Trist e Fred } \\
\text { M. Emery }\end{array}$ & 1960 & $\begin{array}{l}\text { Coordenaram a análise da produtividade e da qualidade de vida no trabalho, } \\
\text { com abordagem dos sistemas sociotécnicos. }\end{array}$ \\
\hline $\begin{array}{l}\text { Robert Rogers } \\
\text { Blake e Jane } \\
\text { Srygley Mouton } \\
\end{array}$ & 1964 & $\begin{array}{l}\text { Criaram o grid gerencial voltado para produtividade, excelência empresarial e } \\
\text { análise da organização como um todo. }\end{array}$ \\
\hline \multicolumn{3}{|r|}{ Segunda geração } \\
\hline Edgar Henry Schein & 1965 & $\begin{array}{l}\text { Contribuiu para estudos psicológicos, liderança e cultura nas organizações, } \\
\text { processos e mudanças organizacionais. }\end{array}$ \\
\hline Warren G. Bennis & 1966 & $\begin{array}{l}\text { Analisou efeitos de mudanças rápidas nas organizações. } \\
\text { Analisou efeitos da organização no futuro, envolvendo questões ambientais, } \\
\text { comunidade, valores de trabalho, tarefas, objetivos, questões motivacionais } \\
\text { (conclusão dos trabalhos em 1973). }\end{array}$ \\
\hline $\begin{array}{l}\text { Paul Roger } \\
\text { Lawrence e Jay } \\
\text { William Lorsh }\end{array}$ & 1967 & $\begin{array}{l}\text { Criaram o modelo de diagnóstico e ação, relações entre organização em } \\
\text { ambiente e a complexidade organizacional. }\end{array}$ \\
\hline Chris Argyris & 1968 & Aprendizado organizacional e processos de mudança. \\
\hline \multicolumn{3}{|r|}{ Terceira geração } \\
\hline William J. Reddin & 1970 & $\begin{array}{l}\text { Criou a teoria 3D da eficácia gerencial, que analisa o deslocamento de estilos e } \\
\text { dimensões de atuação dos profissionais nas organizações. }\end{array}$ \\
\hline M. Maccoly & 1971 & $\begin{array}{l}\text { Criou o perfil da águia, realização de entrevistas detalhadas, testes projetivos } \\
\text { e interpretação dos sonhos. }\end{array}$ \\
\hline $\begin{array}{l}\text { Stuart Atkins e } \\
\text { Allan Katcher }\end{array}$ & 1971 & $\begin{array}{l}\text { Criaram os quatro estilos Lifo, afirmando que o uso exagerado das forças de } \\
\text { uma pessoa transforma-se em fraqueza. }\end{array}$ \\
\hline $\begin{array}{l}\text { Paul Hersey e } \\
\text { Kenneth H. } \\
\text { Blanchard }\end{array}$ & 1972 & Criaram a liderança situacional, evidenciando que cada caso é um caso. \\
\hline
\end{tabular}

Fonte: Adaptado de: OLIVEIRA, 2012.

Percebe-se que os principais idealizadores da teoria do DO realizaram seus estudos até a década de 1970, embora se identifiquem autores contemporâneos que publicaram sobre o tema. Ramos $(1989 ; 1996)$ adverte, em suas obras A nova ciência das organizações (1989) e Redução sociológica (1996), sobre a necessidade de haver um maior refinamento teórico e metodológico para que as ciências administrativas sejam contextualizadas de forma inter-relacionada com o desenvolvimento de um país. Nessa perspectiva, entende-se que a análise do DO deva ocorrer de forma multidisciplinar, tendo como base os conceitos discutidos pela ciência do desenvolvimento regional que podem auxiliar nesse processo, especialmente no estudo das dimensões sistêmicas, estruturais e organizacionais propriamente ditas, tendo em vista a compreensão do DO de forma mais territorializada.

Identifica-se que a elaboração de propostas de Teoria Organizacional Multidimensional (TOM) não significa um tema novo na literatura em gestão empresarial. No Brasil, Ramos (1989) realizou uma discussão epistêmica na obra $A$ 
nova ciência das organizações, em que defende, em linhas gerais, a necessidade de haver um refinamento teórico e metodológico para a literatura em gestão empresarial, além de uma contribuição em nível nacional que contemple as especificidades regionais.

Percebe-se, de forma geral, que o DO apresentado na literatura evidencia uma preocupação com a gestão da mudança centrada em processos realizados por consultorias e em uma gestão de pessoas, muitas vezes contestável de acordo com o prisma crítico. Em termos teóricos, fica evidente que o DO, apresentado como teoria na literatura de gestão, limita-se a uma visão interativa entre a Escola das Relações Humanas, com viés produtivista unicamente, e com uma tentativa de aplicação da visão sistêmica e da Teoria Contingencial, que passou a influenciar também os estudos organizacionais. Entretanto, as características gerais do DO não conseguem dar conta nem da Escola das Relações Humanas, tampouco da visão sistêmica e da Teoria da Complexidade que partilham a multidimensionalidade e a não fragmentação das relações de produção como elementos "coisificantes".

O DOM, a partir de uma visão mais ampla, não focada somente na tríade eficiência, controle e resultado, e não considerando as organizações como espaços isomórficos únicos de acumulação rígida, representa um grande desafio para os estudos organizacionais, para as dinâmicas empresariais e para o desenvolvimento regional. Evidentemente, as organizações, sejam elas privadas, públicas ou comunitárias, necessitam dos elementos descritos na tríade eficiência, controle e resultado, em um pensamento de movimento dos contrários. O que se critica no decorrer deste estudo é a alienação e a fragmentação, no sentido de se pensar que estes são os elementos únicos ou centrais e delineadores de todas as atividades organizacionais.

Cabe ressaltar que os estudos de gestão empresarial estão muito alinhados à ideia de que as organizações são controláveis, estáveis, previsíveis e que os aspectos territoriais e sociais ${ }^{3}$ normalmente não são descritos nessas análises (DIMAGGIO; POWELL, 2005). Entende-se que as organizações não são meros espaços para acumulação rígida de capital, sendo que suas dinâmicas apresentam repercussão social relevante na definição de novos rumos para o desenvolvimento, a partir da sociedade pós-industrial, em ruptura ao modelo tecnoindustrial ainda dominante.

Ramos (1989) contribuiu para essa discussão ao mencionar que o problema na sociedade moderna alicerça-se na cognição humana e não é somente proveniente das relações de produção propriamente ditas, sendo o mercado apenas uma das variáveis em uma multicentralidade, envolvendo a sociedade, a cultura, os indivíduos e os territórios. Nessa perspectiva, apresenta alguns elementos centrais para a discussão da multidimensionalidade organizacional, argumentando que, ao contrário de Weber, ${ }^{4}$ Habermas não suspende os padrões

\footnotetext{
${ }^{3}$ Elementos denominados neste estudo em termos epistemológicos, como uma visão positivista e isomórfica.

${ }^{4}$ Apesar de Weber ter influenciado o funcionalismo, não pode ser considerado um representante da classe burguesa " uma vez que ele encarava esse tipo de racionalidade com evidente desinteresse pessoal”. (RAMOS, 1989 p. 4). Habermas, avança na visão do pensamento crítico ao trazer o pensamento da racionalidade instrumental e substantiva como metodologia de análise social.
} 
éticos quando se volta para o tema da racionalidade nas sociedades modernas, como elementos importantes na medida em que trata dos seguintes temas:

\begin{abstract}
1. A restauração do conceito de um interesse racional que, embora implícito no pensamento político grego, passou a ser tema central dos sistemas filosóficos dos idealistas alemães. 2. Reexame das opiniões históricas de Marx e, especialmente, de sua premissa de que uma sociedade racional iria resultar, necessariamente, do desenvolvimento das forças de produção. 3. Investigação das consequências políticas e psicológicas do domínio da racionalidade instrumental sobre as sociedades modernas. 4. A padronização da comunicação como ponto central de uma teoria social integrativa crítica. Inclina-se ele por uma espécie de crítica integrativa. (RAMOS, 1989, p. 10-11)
\end{abstract}

Identifica-se um processo de reestruturação do conceito de interesse social a partir de uma multicentralidade. Nessa perspectiva, observa-se um destaque na literatura nacional e internacional da tríade econômico, social e ambiental, com vários desdobramentos multidimensionais, razão pela qual, nesta investigação, apresenta-se a proposta baseada em fatores sistêmicos, estruturais e empresariais de Kupfer, Ferraz e Haguenauer (1997). Outro desafio se refere ao reconhecimento da questão social, que repetidamente aparece nas diretrizes organizacionais como elemento que justifica a existência de políticas predominantemente econômicas caracterizadas como "humanistas de fachada" (RAMOS, 1989; TENORIO, 2004).

Outra polêmica se refere à compreensão de que todas as questões estejam vinculadas às relações de produção. Essa revisão apoia-se na reflexão marxista, mas amplia essa discussão para a cognição humana. Morgan (1996) corrobora com essa discussão, mencionando que as relações de produção da sociedade tecnoindustrial criaram uma espécie de taylorismo e fordismo de espírito, ou seja, presente na cognição humana. Entretanto, entende-se que a racionalidade predominante nos ambientes organizacionais é a instrumental, com ênfase da tríade eficiência, controle e resultado econômico, em contraponto à racionalidade substantiva, que teria aspectos multidimensionais, normalmente negligenciados.

A racionalidade instrumental atinge picos no auge da sociedade tecnoindustrial, chegando, contraditoriamente, a prejudicar seu propósito de eficiência e de lucro. Exemplos disso podem ser percebidos no dia a dia em questões como a existência de produtos de baixa qualidade, políticas equivocadas de gestão de pessoas, baixo nível de planejamento tático e estratégico, entre outros.

Todas essas questões vêm imbricadas em um processo de comunicação e de marketing de consumo que não possui um alinhamento mercadológico e de desenvolvimento. Centra-se, na verdade, um olhar para todas as variáveis relevantes em um processo de planejamento organizacional em que, na maioria dos casos, buscam-se ganhos de escala em mercados que não estão mais em expansão.

Historicamente, o desenvolvimento, ainda com base em conceitos de crescimento, passou a ser visto como fruto das organizações produtivistas e das invenções que implementavam novas formas de vida, a exemplo da criação da sociedade de consumo. Dava-se, então, início ao êxodo rural e ao consumo desenfreado frente à oferta de produtos antes inexistentes ou de difícil acesso à 
sociedade. ${ }^{5}$ Paralelamente, criou-se a plebe marginalizada e alienada do desenvolvimento, devido à exploração e à falta de acesso aos bens de capital, tornando-se "objetos" de castas sociais. Observa-se que a visão de desenvolvimento presente na atualidade ainda se encontra vinculada aos conceitos positivistas generalizadores que defendem argumentações como "ordem e progresso", como se a sociedade fosse harmônica e controlável e cujos fatos sociais fossem plenamente generalizáveis, numa visão contrária às matrizes não positivistas.

Salienta-se a importância de pensar em uma análise que ultrapasse a centralidade do mercado e a predominância dos aspectos econômicos, levando em conta outras questões relevantes para a definição de um marco teórico do DOM. Em termos epistemológicos, apresentam-se alguns elementos que se contrapõem à teoria do DO e apontam para a possibilidade de efetivação do DOM, conforme apresentado no Quadro 4.

Quadro 4 - Diferenças entre DO e DOM

\begin{tabular}{|l|l|l|}
\hline \multicolumn{1}{|c|}{ Dimensão } & \multicolumn{1}{c|}{ DO } & \multicolumn{1}{c|}{ DOM } \\
\hline Foco & Mercado & Sociedade \\
\hline Racionalidade & Instrumental & Substantiva \\
\hline Gestão & Hierárquica & Deliberativa \\
\hline Epistemologia & Positivista & Crítica ou reconstrução epistêmica \\
\hline Visão & Crescimento econômico & Desenvolvimento regional \\
\hline
\end{tabular}

Fonte: FONTOURA; DEPONTI, 2017.

O marco teórico apresentado traz um ponto de partida para se pensar no DOM a partir da análise da sociedade, da visão substantiva, da gestão deliberativa e da epistemologia crítica na visão de reconstruções epistêmicas nas organizações e nas suas externalidades.

\section{Considerações finais}

O objetivo geral deste estudo foi identificar se a perspectiva do DOM é teoricamente adequada para explicar os processos de desenvolvimento organizacional em um contexto de desenvolvimento regional. Em função da opção teórica, salienta-se que as conclusões apresentadas não apontam para a elaboração de um modelo na linha da generalização dos achados, mas contribuem para reforçar alguns indicativos já descritos na análise das contradições entre a teoria do DO, descrita na literatura em gestão empresarial, e a possibilidade de DOM, apresentada neste artigo, com reflexões alternativas para nortear possíveis dinâmicas organizacionais regionalizadas.

O marco teórico para se pensar em dinâmicas organizacionais com base no DOM parte da análise de sua inter-relação com o modelo de DO descrito na literatura em gestão empresarial. Esse marco teórico se embasou na epistemologia crítico-reflexiva, em contraponto aos modelos positivistas que visam à generalização massificada, muitas vezes orientados por estudos de caso direcionados, tendo em vista a elaboração de modelos para analisar organizações como se elas fossem espaços mecanomórficos.

\footnotetext{
${ }^{5}$ Elementos evidenciados em Wittmann e Fontoura (2016).
} 
Em suma, o marco teórico evidenciou, à luz de Ramos (1989), algumas questões históricas já apresentadas por Marx (1974) em relação à necessidade de haver uma reflexão sobre as formas de organização da produção, envolvendo aspectos epistemológicos como contradições entre o DO e o possível DOM, para explicação de processos de desenvolvimento das organizações em uma visão crítica da formação de paradigmas, conforme De Paula (2015).

O conceito de competitividade, nesse prisma, assim como definido no marco teórico, passa por um processo de reanálise, contrapondo-se à visão baseada no mercado, defendida por Porter (1986), encaminhando-se para modelos mais regionalizados, baseados nas demandas das localidades e na cooperação entre as empresas, tendo várias possibilidades de estratégias.

As proposições identificadas no marco teórico para o DOM, alinham-se às críticas ao modelo porteriano de posicionamento estratégico baseado na tríade liderança em custos, diferenciação e enfoque, ampliando conceitos sociológicos de pertencimento às regiões, de questionamento sobre o impacto das atividades, de visão de mundo em relação às formas de organização da produção e à cognição humana.

Considera-se que o DOM é adequado para explicar e auxiliar em processos de desenvolvimento e planejamento organizacional porque apresenta um arcabouço para reflexão multidimensional nas organizações, em contraponto à visão unidimensional do DO, como teoria e como instrumento de gestão organizacional.

Como sugestão de novos estudos, evidencia-se uma agenda de pesquisa para o DOM, que envolve aspectos das ciências sociais aplicadas (Economia, Contabilidade, Administração) e também de relevância para a ciência do desenvolvimento regional, visto que a literatura e as práticas organizacionais ainda apresentam uma dependência muito forte da literatura internacional, principalmente da norte-americana, embora o Brasil tenha uma série de particularidades em função de questões sociais, culturais, políticas e territoriais.

Por fim, com base nos elementos referidos, apresenta-se a seguinte tese: 0 DO não apresenta pressupostos teóricos e metodológicos para ser definido como teoria, por não contemplar a multidimensionalidade econômica, social e ambiental. As organizações, por sua vez, constituem-se uma possibilidade de campo de estudo para o DOM, em função dos seus aspectos territoriais, em uma caminhada não paradigmática de reconstruções epistêmicas.

\section{REFERÊNCIAS}

BELL, D. Las contradicciones culturales del capitalismo. Madrid: Alianza, 1977.

. The coming of Post-Industrial Society. New York: Basic Books, 1973.

BENKO, G. A ciência regional. Oeiras: Celta, 1999.

BENNIS, W. G. Desenvolvimento organizacional: sua natureza, origens e perspectivas. São Paulo: Edgard Blucher, 1972. 
Desenvolvimento Organizacional Multidimensional: uma perspectiva crítica para os estudos organizacionais

BOLTANSKI, L.; CHIAPELLO, E. O novo espírito do capitalismo. São Paulo: Martins Fontes, 2009.

CARAVANTES, G. R.; PANNO, C. C.; KLOECKNER, M. C. Administração: teorias e processo. São Paulo: Pearson Prentice Hall, 2005.

DE PAULA, A. P. P. Para além dos paradigmas nos Estudos Organizacionais: o Círculo das Matrizes Epistêmicas. Cadernos EBAPE. BR, Rio de Janeiro, v. 14, n. 1, p. 24-46, jan./mar. 2016.

DE PAULA, Ana Paula Paes. Repensando os estudos organizacionais: para uma nova teoria do conhecimento. Editora FGV, 2015.

DIMAGGIO J. P.; POWELL W. S. A gaiola de ferro revisitada: isomorfismo institucional e a racionalidade coletiva nos campos organizacionais. RAE, Rio de Janeiro, v. 45, n. 02, abr./jun. 2005.

ETGES, V. E. Desenvolvimento regional sustentável: o território como paradigma. Santa Cruz do Sul: Redes, 2005.

ETGES, V. E; DEGRANDI, O. J. Desenvolvimento regional: a diversidade regional como potencialidade. Revista Brasileira de Desenvolvimento Regional, Blumenau, p. $85-94$, out. 2013.

FONTOURA, F. B. B.; MACHADO, C. D. Afinal o que é desenvolvimento organizacional? SEMINÁRIO INTERNACIONAL SOBRE DESENVOLVIMENTO REGIONAL, 8, 2017, Santa Cruz do Sul. Anais... Santa Cruz do Sul: Edunisc, 2017.

FONTOURA F. B. B.; WITTMANN, M. L. Organizações e desenvolvimento: reflexões epistemológicas. Revista do Cepe, Santa Cruz do Sul, n. 43, p. 101-118, jan./jun. 2016.

GRZYBOVSKI, D. A contribuição do desenvolvimento organizacional para promover mudanças na dinâmica dos sistemas sociais. VIII ENCONTRO DE ESTUDOS ORGANIZACIONAIS DA AMPAD, 8, 2018, Gramado. Anais... Gramado: AMPAD, 2014.

HARVEY, D. A condição pós-moderna. São Paulo: Loyola, 1992.

HORKHEIMER, M. Teoria crítica. Buenos Aires: Amorrurtu, 1974.

HORKHEIMER, M.; ADORNO, W. T. Dialética do esclarecimento: fragmentos filosóficos. Rio de Janeiro: Jorge Zahar, 1985.

KUHN, T. S. A estrutura das revoluções científicas. São Paulo: Perspectiva, 2005.

KUPFER, D.; FERRAZ, J. C.; HAGUENAUER, L. Made in Brazil: desafios competitivos para a indústria. Rio de Janeiro: Campus, 1997. 
MALTHUS, T. R. Ensaio sobre população. São Paulo: Abril Cultural, 1982.

MARCUSE, H. A ideologia da sociedade industrial: o homem unidimensional. Tradução Giasone Rebuá. Rio de Janeiro: Zhar, 1973.

MARX, K. O capital: crítica da economia política. Rio de Janeiro: Civilização Brasileira, 1974.

MORGAN, G. Imagens da organização. São Paulo: Atlas, 1996.

MORIN, E. Introdução ao pensamento complexo. Porto Alegre: Sulina 2011.

OLIVEIRA, D. P. R. Teoria geral da administração: uma abordagem prática. São Paulo: Atlas, 2012.

POPPER, K. R. A lógica da pesquisa científica. São Paulo: Cultrix, 2004

PORTER, Michael E. Estratégia Competitiva. Rio de Janeiro: Ed. Campos, 1986.

RAMOS, A. G. A nova ciência das organizações: uma reconceituação da riqueza das nações. Rio de Janeiro: FGV, 1989.

. A redução sociológica. Rio de Janeiro: UFRJ, 1996.

RICARDO, D. Princípios de economia política e tributação. São Paulo: Abril Cultural, 1982.

SCATOLIN, F. D. Indicadores de desenvolvimento: um sistema para o Estado do Paraná. 1989. Dissertação (Mestrado em Economia) - Universidade Federal do Rio Grande do Sul, Porto Alegre, 1989.

SMITH, A. A riqueza das nações: investigação sobre a natureza e suas causas. São Paulo: Nova Cultural, 1996.

SOBRAL, F.; PECl, A. Administração: teoria e prática no contexto brasileiro. São Paulo: Pearson Prentice Hall, 2013.

TENÓRIO, G. F. A unidade dos contrários: fordismo e pós-fordismo. RAP, Rio de Janeiro, 2011. 1998. . Gestão social: uma perspectiva conceitual. RAP, Rio de Janeiro, set./out., . Tecnologia da informação transformando as organizações e o trabalho. Rio de Janeiro: FGV, 2007. 
Desenvolvimento Organizacional Multidimensional: uma perspectiva crítica para os estudos organizacionais

. Tem razão a administração? Ensaios de teoria organizacional. Ijuí: Unijuí, 2004.

TOFFLER, A. Powershift, as mudanças de poder: um perfil da sociedade do século XXI pela análise das transformações e natureza do poder. Rio de Janeiro: Record, 1995.

TRINDADE, H. (Org.). O Positivismo: teoria e prática. 3. ed. Porto Alegre: UFRGS, 2007.

WITTMANN, M. L.; FONTOURA, F. B. B. Desenvolvimento e organizações: uma análise a partir da matriz positivista. In: SEMINÁRIO DE DESENVOLVIMENTO REGIONAL, ESTADO E SOCIEDADE, 3, Blumenau, 2016. Anais..., Blumenau-SC: FURB, 2016.

ZIEMER, R. Mitos organizacionais: o poder invisível na vida das empresas. São Paulo: Atlas, 1996.

Fernando Batista Bandeira da Fontoura. Mestre em Administração, Doutor em Desenvolvimento Regional, professor na Universidade de Santa Cruz do SulUnisc.fbfontoura@unisc.br

Fernando Guilherme Tenório. Fundação Getulio Vargas, Escola Brasileira de Administração Pública e de Empresas.

Como citar: FONTOURA, Fernando Batista Bandeira da; TENÓRIO, Fernando Guilherme. Desenvolvimento Organizacional Multidimensional: uma perspectiva crítica para os estudos organizacionais. Redes (St. Cruz Sul, Online), Santa Cruz do Sul, v. 25, n. 2, p. 590-609, abr. 2020. ISSN 1982-6745. Disponível em:

https://online.unisc.br/seer/index.php/redes/article/view/14549 Acesso em: 15 maio 2020. doi: https://doi.org/10.17058/redes.v25i2.14549

\section{CONTRIBUIÇÃO DE CADA AUTOR}

a. Fundamentação teórico-conceitual e problematização: Fernando Guilherme Tenório e Fernando Batista Bandeira da Fontoura

b. Pesquisa de dados e análise estatística: Fernando Batista Bandeira da Fontoura

c. Elaboração de figuras e tabelas: Fernando Batista Bandeira da Fontoura

d. Fotos: não se aplica

e. Elaboração e redação do texto: Fernando Batista Bandeira da Fontoura

f. Seleção das referências bibliográficas: Fernando Batista Bandeira da Fontoura e Fernando Guilherme Tenório

Fontes de financiamento: não se aplica. 